\title{
Investigation of the Optical, Structural and Compositional Properties of Electrodeposited Lead Manganese Sulfide (PbMnS) Thin Films for Possible Device Applications
}

\author{
Laz Nnaedozie Ezenwaka ${ }^{1}$, Augustine Nwode Nwori $^{{ }^{*}}{ }^{\mathbb{B}}$, Ifeyinwa Euphemia Ottih ${ }^{1}$, Ngozi Agatha \\ Okereke $^{1}$, Nonso Livinus Okoli $^{2}$ (일 \\ ${ }^{1}$ Department of Industrial Physics, Faculty of Physical Science, Chukwuemeka Odumegwu Ojukwu University Uli, Anambra State, \\ Nigeria \\ ${ }^{2}$ Department of Physics and Electronics, Faculty of Natural and Applied Sciences, Legacy University Okija, Anambra State, Nigeria \\ Email: austine2010forreal@yahoo.com
}

Received: 02 November 2021; Revised: 30 November 2021; Accepted: 07 December 2021

\begin{abstract}
The properties of PbMnS semiconductor thin films deposited on fluorine-doped tin oxide (FTO) substrate using an electrodeposition method are investigated to determine their possible device applications. Lead acetate, manganese sulfate, and thiourea were used as precursors for sources of lead, manganese, and sulfur ions respectively. The concentration of lead, manganese, and sulfur ions sources with deposition voltage of $1.8 \mathrm{~V}$ was kept constant. The films were deposited using three electrodes system of electrodeposition method by varying deposition time. The films were characterized for optical, structural, morphological, and compositional properties and results showed that the absorbance, refractive index, and optical conductivity of the films are high in the visible (VIS) and near-infrared (NIR) regions but decreases in the NIR. These three properties initially increased with an increase in deposition time up to a time of $70 \mathrm{~s}$ which has the highest values of these properties before decreasing to lower values. The transmittance and extinction coefficient of the films are low in both VIS and NIR regions. The bandgap energy of PbS was found to be blue shifted with values of $1.51 \mathrm{eV}, 1.54 \mathrm{eV}, 1.60 \mathrm{eV}, 1.45 \mathrm{eV}$, and $1.35 \mathrm{eV}$ for the films deposited at $30 \mathrm{~s}, 50 \mathrm{~s}, 70 \mathrm{~s}$, $90 \mathrm{~s}$, and $110 \mathrm{~s}$ respectively. XRD analysis showed that the films are crystalline with sharp peaks positions indexable to crystalline planes of (111), (200), (211), (220), (311) and (400) with average crystallite size in the range of 16.110 $\mathrm{nm}$ to $17.218 \mathrm{~nm}$. Energy-dispersive X-ray spectroscopy (EDX) results showed that the films are composed of lead, manganese, and sulfur but there are some impurity elements present mostly as a result of the substrate used. These properties exhibited by the deposited thin films of PbMnS showed that they can be used for many optoelectronic applications such as photovoltaic cells, sensors, photoconductors, etc.
\end{abstract}

Keywords: thin films, electrodeposition, bandgap, X-ray diffraction (XRD), photodetectors, photovoltaic cells

\section{Introduction}

Lead sulphide has been described as a group IV-VI semiconductor material with a narrow bandgap $(0.41 \mathrm{eV})$ and large excitation Bohr' radius $(18 \mathrm{~nm})$ and has demonstrated good promise for copious applications including

Copyright (C2021 Augustine Nwode Nwori, et al.

DOI: https://doi.org/10.37256/nat.3120221226

This is an open-access article distributed under a CC BY license

(Creative Commons Attribution 4.0 International License)

https://creativecommons.org/licenses/by/4.0/ 
photovoltaic solar cells, luminescent devices, photochemical cell, diode laser and for many other optoelectronic devices, [1-2]. These phenomena have made PbS stand out from other groups of semiconductor materials such as II-VI and III-V, thus offering the opportunities to study the rudiments of physics of quantum confinement in the material as a result of its large exciton Bohr radius [3]. Quantum confinement in $\mathrm{PbS}$ thin films gives rise to broader bandgap energy (that is; bandgap energy is increased due to the quantum size effect/size reduction compared with the bulk PbS semiconductor) and as such many interesting structural, optical, and electrical properties which are much different from their bulk material counterparts are obtained. This singular behaviour placed $\mathrm{PbS}$ thin films as a good material for light absorbers applications in solar cells, transistors, infrared detectors, biosensors devices, light-emitting diode (LED) devices, lasers, telecommunications, optical switches, optical amplification, and gas-sensing agents in the solid-state sensors [4-6].

Incorporation of different elements (dopant ions) in the composition of the host semiconductor crystals such as $\mathrm{PbS}$ has also demonstrated alteration of various properties such as the control of the bandgap energy and change in the positions of the Fermi level of the semiconductor thin films [7-10]. The elements such as iron (Fe), manganese (Mn), nickel (Ni), cobalt (Co) have been known to possess self-induced spin electronic properties and as such can trigger highperformance potentials in the semiconductor materials they are incorporated for many device applications. The highperformance potentials are attributed to sizeable numbers of the ions of such elements $\left(\mathrm{Mn}^{2+}, \mathrm{Fe}^{2+}, \mathrm{Co}^{2+}\right.$, etc) that give rise to varieties of cooperative effects through the process of spin-spin exchange interactions [11-12]. For instance, the influence of $\mathrm{Mn}$ doping has been reported to cause broadening of the electronic bandgap energy in the PbS quantum dots (QDs) with the sp-d hybridization between the PbS host material and Mn dopants being attributed to being the responsible factor for the bandgap broadening [13]. Mn-doped lead sulfide (PbS) thin films grown on glass substrate but using successive ionic layer adsorption and reaction (SILAR) deposition method have also been reported by [14]. The authors concluded through a vibrating sample magnetometer (VSM) study that the grown films exhibited multi-domain behaviour and as such behave as soft magnetic material. Effects of manganese dopant on the structure, morphology, and optical properties of the nano lead sulfide thin film have equally been reported by [15] and concluded that Mn doping has structure-properties correlating effects on the nano $\mathrm{PbS}$ film and can be used to tune the film's texture in the nano and microcrystalline structure ranges. The influence of Ba doping on the properties of $\mathrm{PbS}$ thin films prepared by the SILAR method reported by [16] have shown that Ba-doping concentration has influenced the size of the thin film's nanoparticles and optical bandgap energy of the films were found to increase as Ba-doping concentration is increased. The influence of some other materials including manganese used as dopant on $\mathrm{PbS}$ thin films prepared using different deposition methods have been reported as given by [17-19].

In this paper, the aim is to investigate the optical, structural and morphological properties as well the compositions of the PbMnS thin films prepared using an electrodeposition method to determine their possible device applications.

\section{Materials and methods}

The semiconductor thin films of PbMnS were deposited on fluorine tin oxide (FTO) glass substrate using an electrodeposition method at room temperature. Lead acetate supplied by Guangdong Guanghua Sci.-Tech Co., Ltd, manganese sulphate $\left(\mathrm{MnSO}_{4} \cdot \mathrm{H}_{2} \mathrm{O}\right)$ supplied by Guangdong Guanghua Sci.-Tech Co., Ltd and thiourea $\left(\mathrm{CH}_{4} \mathrm{~N}_{2} \mathrm{~S}\right)$ supplied by Guangdong Guanghua Sci.-Tech Co, Ltd were the precursors used to serve as sources of lead, manganese, and sulphur ions respectively. Sodium tri-sulphate $\left(\mathrm{Na}_{2} \mathrm{SO}_{3}\right)$ supplied by Qualikens Laboratory Reagent and Ethylenediaminetetraacetic acid (EDTA) supplied by Hangzhou Lingui Chemical Co. Ltd was used to serve as supporting electrolyte and complexing agents respectively. The FTO glass substrate which served as a working electrode was washed with acetone in an ultrasonic machine for one hour and dried in an electric oven before its use as a cathode electrode. The platinum rod was used as a counter electrode and its surface was thoroughly cleaned before its use for free flow of current. Silver/Silver chloride $(\mathrm{Ag} / \mathrm{AgCl})$ electrode (with concentration of $3.5 \mathrm{M}$ potassium chloride solution) was used as a reference electrode. Three electrode system configuration of electrodeposition was adopted to deposit the thin films of PbMnS using a potentiostat (model Zhaoxin: RXN-3010D) which served as DC supply unit and was set at a constant voltage of $1.8 \mathrm{~V}$. The electrodeposition method was preferred in this work because it is costeffective as it requires less sophisticated tools and apparatus. In addition, the method deposits films on the target areas as the substrate used are highly conductive. The experimental details and procedures involved a variation of deposition time while keeping the concentrations and volume of other parameters constant as summarized and presented in Table 1. 
A total of five samples were produced and are named as shown in Table 1.

Table 1. Summary of preparation of the PbMnS thin films

\begin{tabular}{|c|c|c|c|c|c|c|c|c|c|c|c|}
\hline \multirow[t]{2}{*}{ Bath Name } & \multicolumn{2}{|c|}{ Pb-acetate } & \multicolumn{2}{|c|}{$\mathrm{MnSO}_{4} \cdot \mathrm{H}_{2} \mathrm{O}$} & \multicolumn{2}{|c|}{$\mathrm{CH}_{4} \mathrm{~N}_{2} \mathrm{~S}$} & \multicolumn{2}{|c|}{ EDTA } & \multicolumn{2}{|c|}{$\mathrm{Na}_{2} \mathrm{SO}_{3}$} & \multirow[t]{2}{*}{ Volt (V) } \\
\hline & $\begin{array}{l}\text { Conc. } \\
\text { (Mol) }\end{array}$ & $\begin{array}{c}\text { Vol } \\
(\mathrm{ml})\end{array}$ & $\begin{array}{l}\text { Conc. } \\
\text { (Mol) }\end{array}$ & $\begin{array}{l}\text { Vol. } \\
\text { (ml) }\end{array}$ & $\begin{array}{l}\text { Conc. } \\
\text { (Mol) }\end{array}$ & $\begin{array}{l}\text { Vol. } \\
\text { (ml) }\end{array}$ & $\begin{array}{l}\text { Conc. } \\
\text { (Mol) }\end{array}$ & $\begin{array}{c}\text { Vol } \\
(\mathrm{ml})\end{array}$ & $\begin{array}{l}\text { Conc. } \\
\text { (Mol) }\end{array}$ & $\begin{array}{l}\text { Vol } \\
\text { (ml) }\end{array}$ & \\
\hline & 0.2 & 10 & 0.1 & 10 & 0.1 & 10 & 0.025 & 5.0 & 0.05 & 10 & 1.80 \\
\hline Deposition Time (s) & \multicolumn{2}{|c|}{30} & \multicolumn{2}{|c|}{50} & \multicolumn{2}{|c|}{70} & \multicolumn{2}{|c|}{90} & \multicolumn{2}{|c|}{110} & \\
\hline
\end{tabular}

The deposited thin films of $\mathrm{PbMnS}$ were annealed at a temperature of $250{ }^{\circ} \mathrm{C}$ for five minutes to improve their quality and characterized for the optical properties using 756S UV-VIS Spectrophotometer, structural properties using EMPYREAN Diffractometer. The morphological properties and elemental composition of the films were investigated using MIRA 3 TESCAN scanning electron microscope (SEM).

\section{Results and discussion}

\subsection{Optical properties}

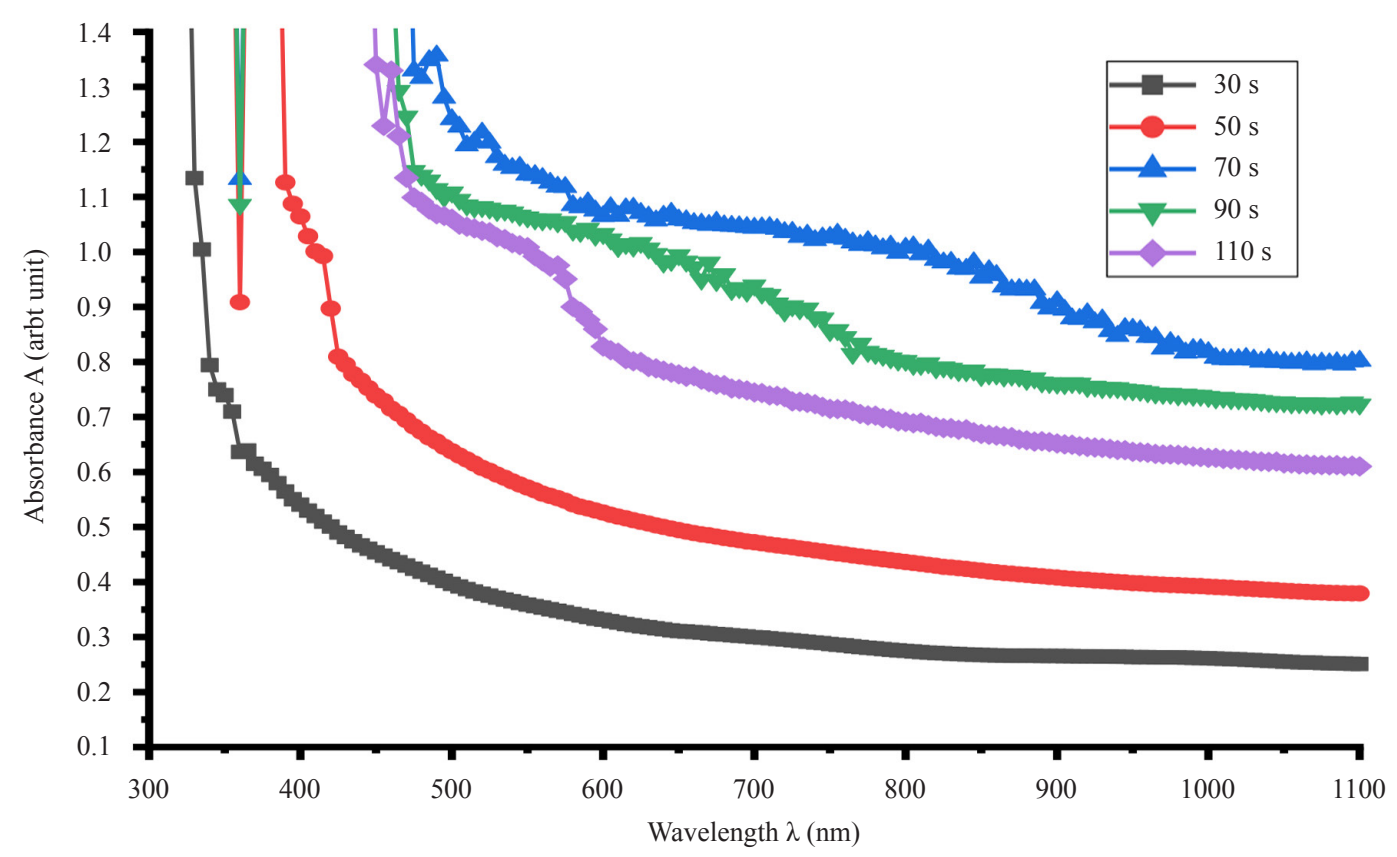

Figure 1. Graph of absorbance against wavelength for the deposited films

The spectral absorbance of the deposited thin films PbMnS was measured directly from the UV-VIS spectrophotometer machine and the plot of the absorbance as a function of wavelength is presented in Figure 1. The figure shows that the absorbance of the films is generally high but decreases with an increase in wavelength. The figure also indicates that the absorbance of the films initially increased with an increase in deposition time but decreased as 
time passed $70 \mathrm{~s}$. This result also suggests that absorbance of the films increases with an increase in deposition time up to critical time (given finite size) and decreases with a further increase in time. The peak absorbance of the thin film deposited at $70 \mathrm{~s}$ is due to the maximum thickness of $321.49 \mathrm{~nm}$ observed. As deposition time increased from $70 \mathrm{~s}$ to $110 \mathrm{~s}$, absorbance was found to decrease in line with a decrease in film thickness. High absorption of the film deposited under $70 \mathrm{~s}$ could also be attributed to an increase in particle sizes as could be confirmed in the SEM image of Figure 9. The high absorbance value of the deposited thin films of PbMnS positioned them for solar photovoltaic applications for harnessing solar energy as their absorption band is a good match to the solar spectrum.

The transmittance $(T)$ of the deposited thin films of PbMnS was calculated using the relation as given by [20].

$$
T=10^{-A}
$$

Where $A$ is the absorbance of the films.

In Figure 2, the graph of the percentage transmittance of the films as a function of wavelength is presented. The figure shows that the transmittance of the films is low but increases with an increase in wavelength. It however decreases with an increase in deposition time up to $70 \mathrm{~s}$ and started to increase slowly as the time of deposition increased further.

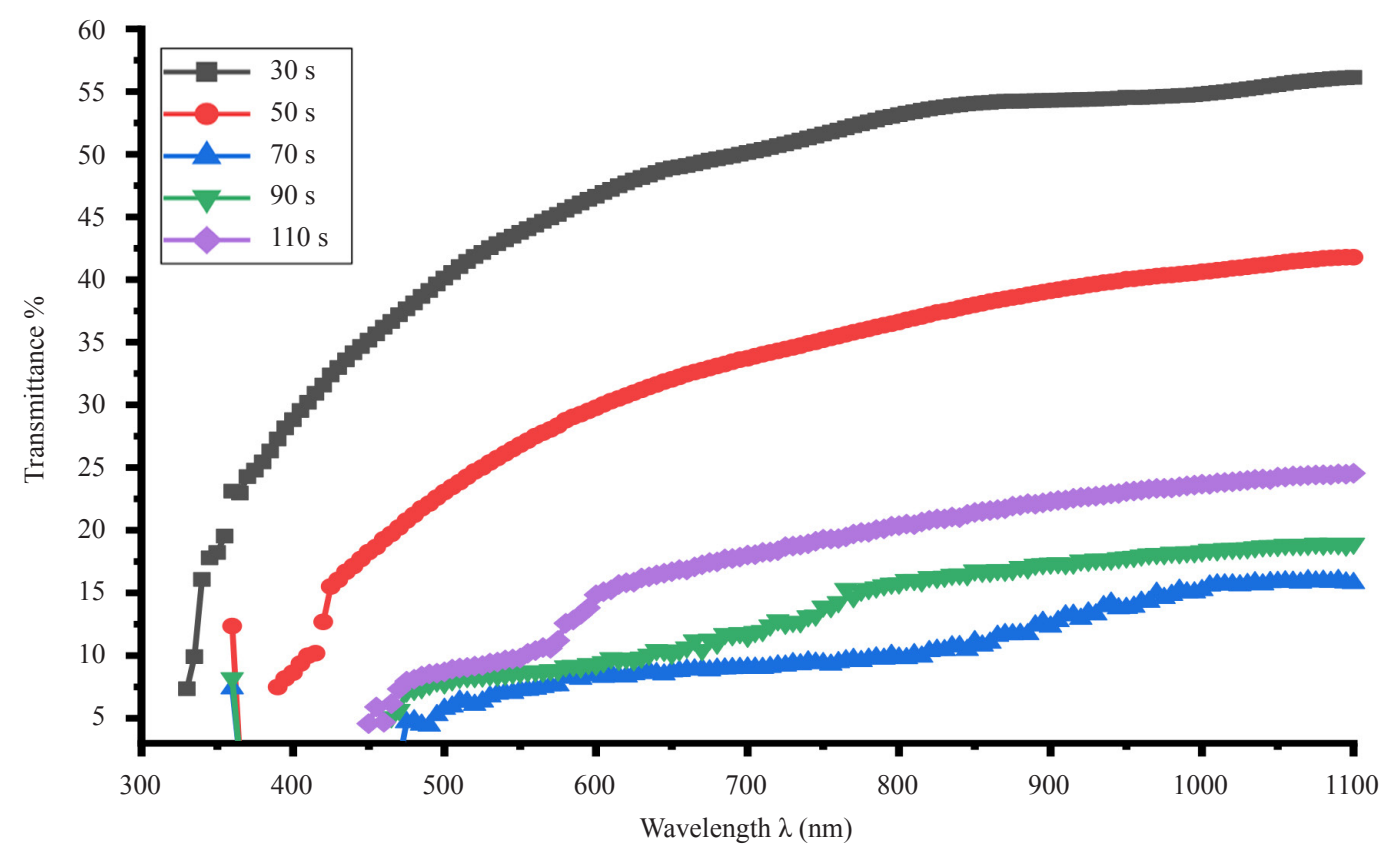

Figure 2. Graph of percentage transmittance against wavelength for the deposited films

The reflectance $(R)$ of the films was obtained from the relation as given by [21].

$$
T=(1-R)^{2} e^{-A}
$$

Re-arranging and making use of equation 1 gives;

$$
R=1-\left(\frac{e}{10}\right)^{\frac{A}{2}}
$$


Where $A$ is the absorbance and e is the Euler's number. The plot of percentage reflectance of the films against wavelength is displayed in Figure 3. The figure indicates that the films reflect moderately in the VIS and NIR regions. The reflectance of the films showed an increase with deposition time up to the time of $70 \mathrm{~s}$ and thereafter decreased to a lower value as time increased further to $90 \mathrm{~s}$ and $110 \mathrm{~s}$. The film deposited at $70 \mathrm{~s}$ has the highest percentage reflectance in the range of $45-60 \%$ while the film deposited at $30 \mathrm{~s}$ has the lowest percentage reflectance of the order $15-40 \%$ throughout the VIS and NIR regions.

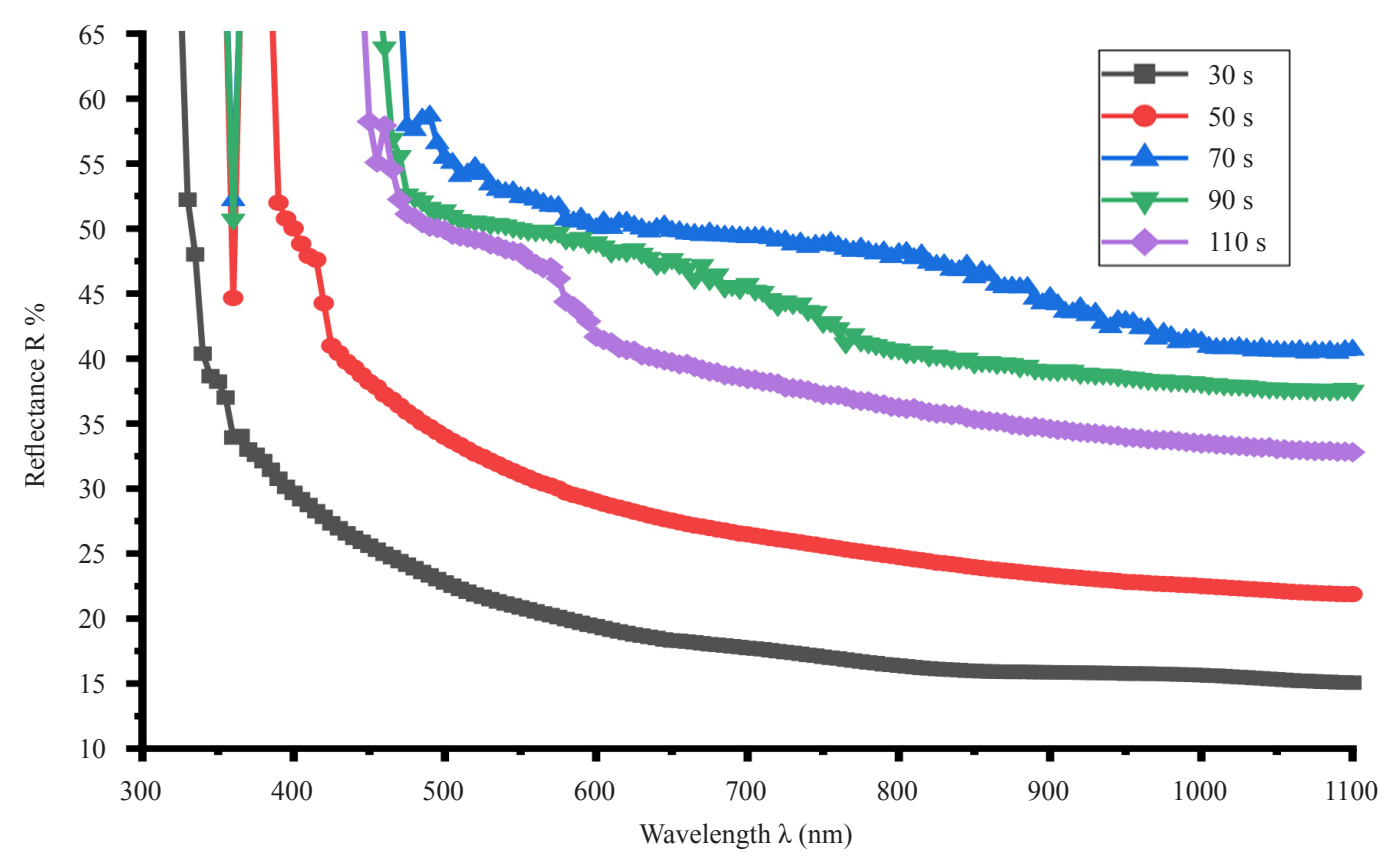

Figure 3. Graph of reflectance against wavelength for the deposited films

Refractive index $(\eta)$; the films' refractive index was calculated using the relation as given by [22].

$$
\eta=\frac{1+\sqrt{R}}{1-\sqrt{R}}
$$

Figure 4 shows the graph of the refractive index of the films against wavelength. From the figure, it is observed that the refractive index of the films is high both in the VIS and NIR regions but decreases towards the NIR region. The refractive index initially increased with an increase in the deposition time but decreased after the deposition time of $70 \mathrm{~s}$. The films deposited at $70 \mathrm{~s}$ has the highest value in the range of 4.75-7.0 while the film deposited at $30 \mathrm{~s}$ has the lowest value in the range of 2.25-4.5 throughout the VIS and NIR regions. The high value of the refractive index exhibited by the films can be attributed to the high absorbance of the films and as such speed of light can be lowered in the films. This is because a high portion of the light energy can be absorbed by the films. This particular property places the films for waveguide applications.

The extinction coefficient $(\kappa)$ of the deposited thin films of PbMnS was calculated using the relation as given by [23].

$$
\kappa=\frac{\alpha \lambda}{4 \pi}
$$




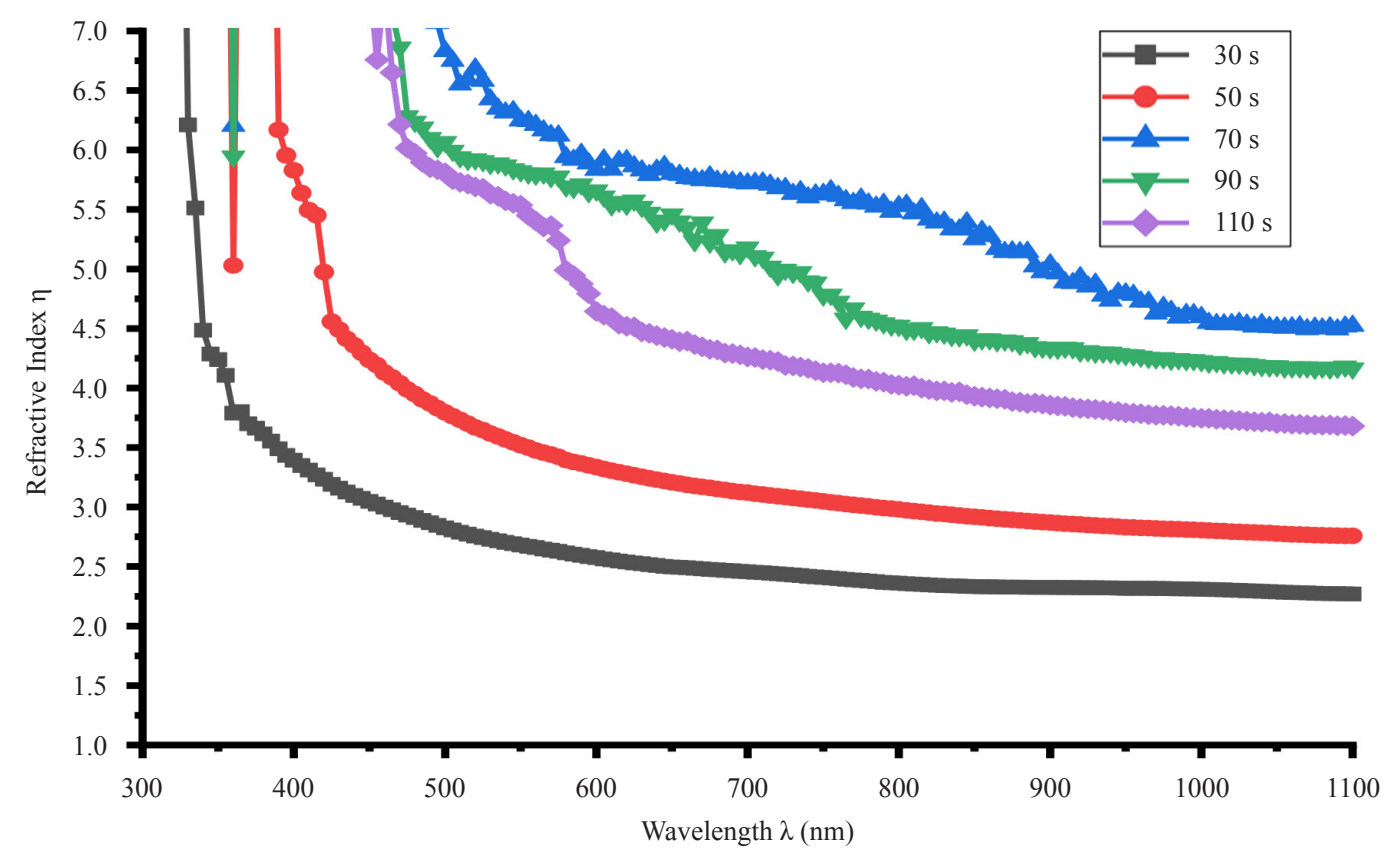

Figure 4. Graph of the refractive index against wavelength for the deposited films

The plot of extinction coefficient against wavelength for the thin films is shown in Figure 5. The figure shows that the extinction coefficient of the films is low except for the film deposited at $70 \mathrm{~s}$ which has an extinction coefficient value in the range of 2.25-5.0. The low value of the extinction coefficient possessed by the films further confirms the suitability of the films for solar cell and photodetector applications since the rate at which photon energy is lost in the material is quite low.

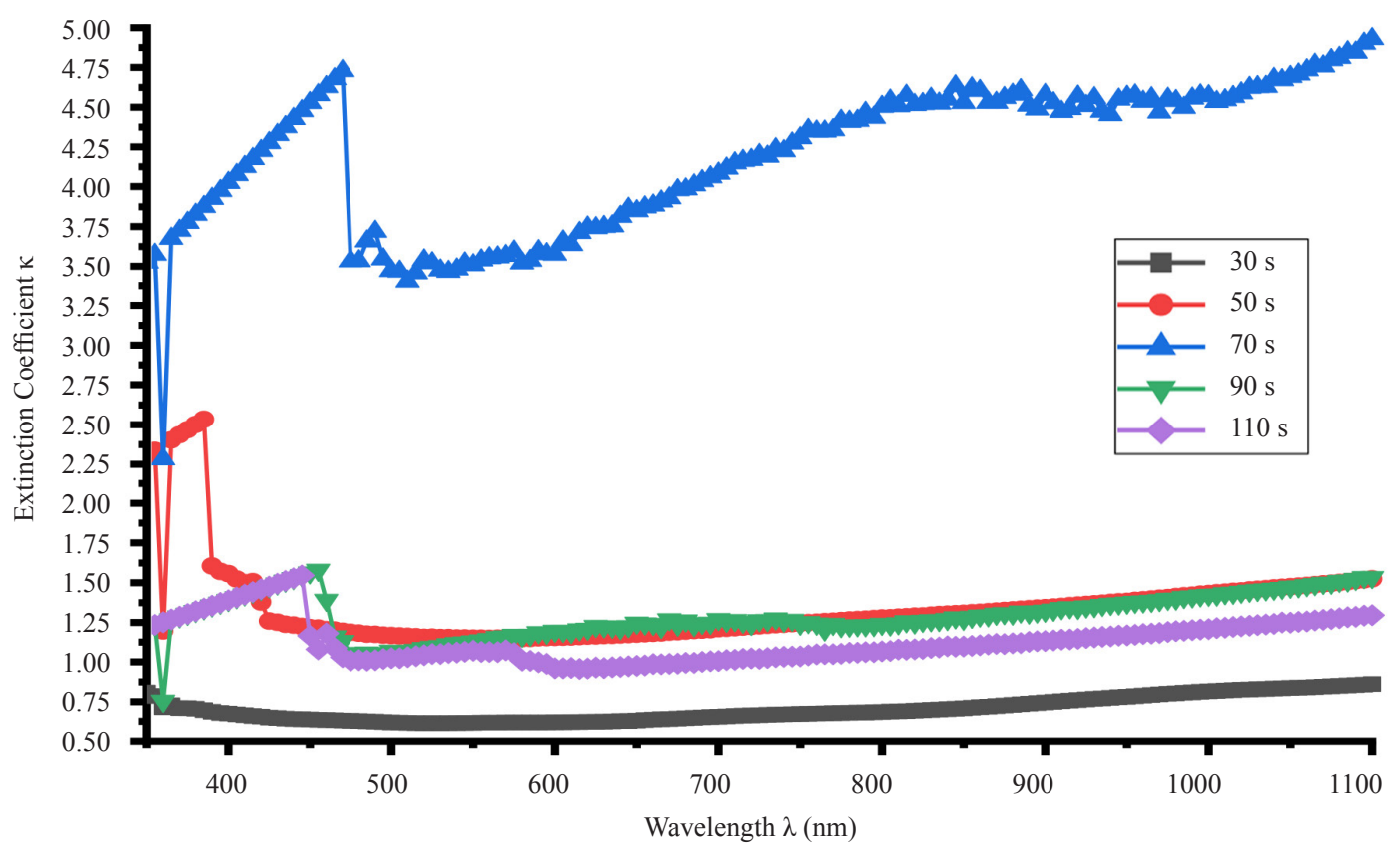

Figure 5. Graph of Extinction coefficient against wavelength for the deposited films 
The optical conductivity $(\sigma)$ of the thin films was calculated using the relationship given by [24].

$$
\sigma=\frac{\alpha \eta C}{4 \pi}
$$

Where $\alpha$ is the absorption coefficient, $\eta$ is the refractive index, and $C$ is the speed of light. The plot of the optical conductivity of the deposited thin films of $\mathrm{PbMnS}$ as a function of wavelength is shown in Figure 6. The figure shows that the optical conductivity of the films is generally high throughout the VIS and NIR regions but decreases in the NIR region. The optical conductivity of the films initially increased with an increase in deposition time but decreased as deposition time passed $70 \mathrm{~s}$. These changes in the optical conductivity of the films make them suitable materials for photoconductor applications.

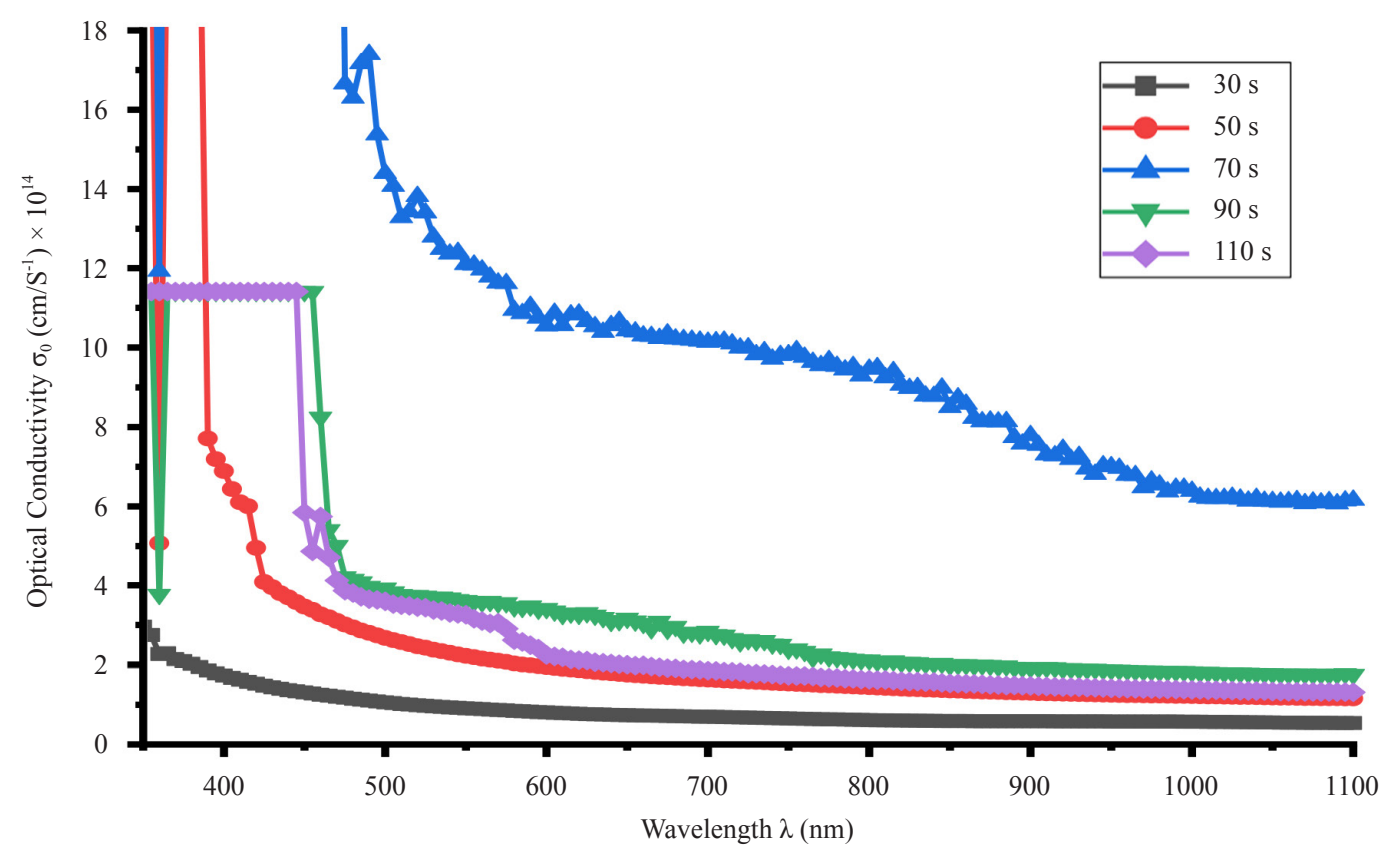

Figure 6. Graph of optical conductivity against wavelength for the deposited films

The bandgap energy of the thin films of PbMnS was calculated using the relation as given by [25-27].

$$
(\alpha h v)=A\left(h v-E_{g}\right)^{n}
$$

Where $\alpha$ is the absorption coefficient of the films, $\mathrm{h} v$ is the photon energy, $A$ is a constant factor, $E_{g}$ is the energy bandgap, and " $n$ " is the transition type factor; which gives direct allowed transition for $n$ equals to $1 / 2$ and indirect allowed transition for $n$ equals to 2. The absorption coefficient $(\alpha)$ used in equations 5 and 6 was calculated using the relation as given in [28].

$$
\alpha=\frac{1}{t_{f}} \ln \left[\frac{(1-R)^{2}}{T}\right]
$$

Where $T, R$, and $t_{f}$ are the transmittance, reflectance, and thickness of the films respectively. The thickness of the 
films was obtained by the gravimetric method according to the relation as given by [29-30].

$$
t_{f}=\frac{M}{\rho S_{a}}
$$

Where $M$ represents the mass of the thin films deposited on the surface of the FTO glass substrate, which was calculated via equation (10).

$$
M=m_{2}-m_{1}
$$

Where $m_{1}$ is the mass of plain FTO glass before film deposition, $m_{2}$ is the mass-weighted by the FTO glass after film deposition, $\rho$ is the average of the bulk densities $\left(7.515 \mathrm{~g} / \mathrm{cm}^{2}\right)$ of $\mathrm{PbS}\left(7.6 \mathrm{~g} / \mathrm{cm}^{3}\right)$ and $\mathrm{Mn}\left(7.43 \mathrm{~g} / \mathrm{cm}^{3}\right)$, while $S_{a}$ is the surface area of the thin films on the substrate. The calculated values of the film thickness using this technique are $107.25 \mathrm{~nm}, 140.52 \mathrm{~nm}, 321.49 \mathrm{~nm}, 225.68 \mathrm{~nm}$, and $177.25 \mathrm{~nm}$ for the films deposited at $30 \mathrm{~s}, 50 \mathrm{~s}, 70 \mathrm{~s}, 90 \mathrm{~s}$, and $110 \mathrm{~s}$ respectively.
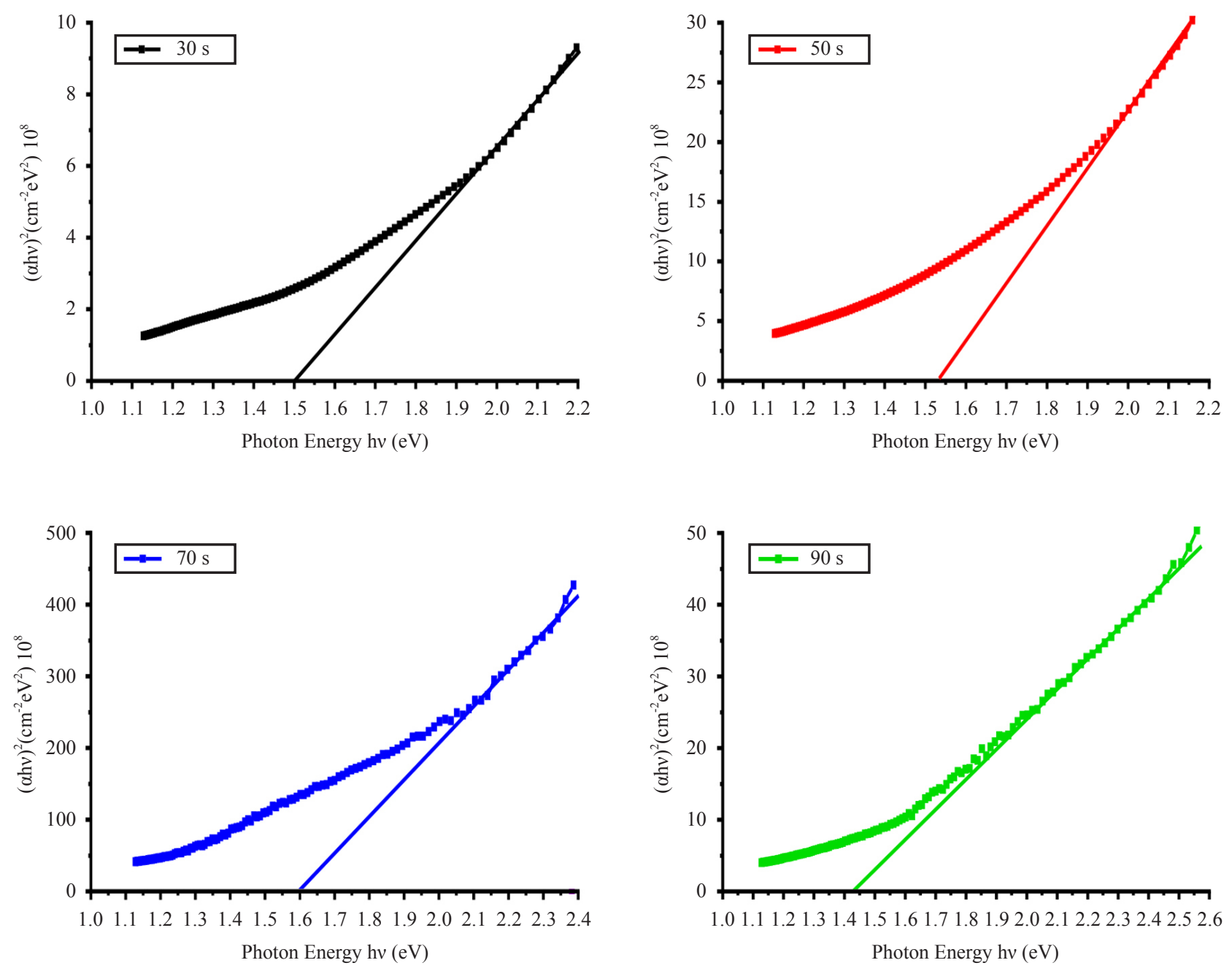


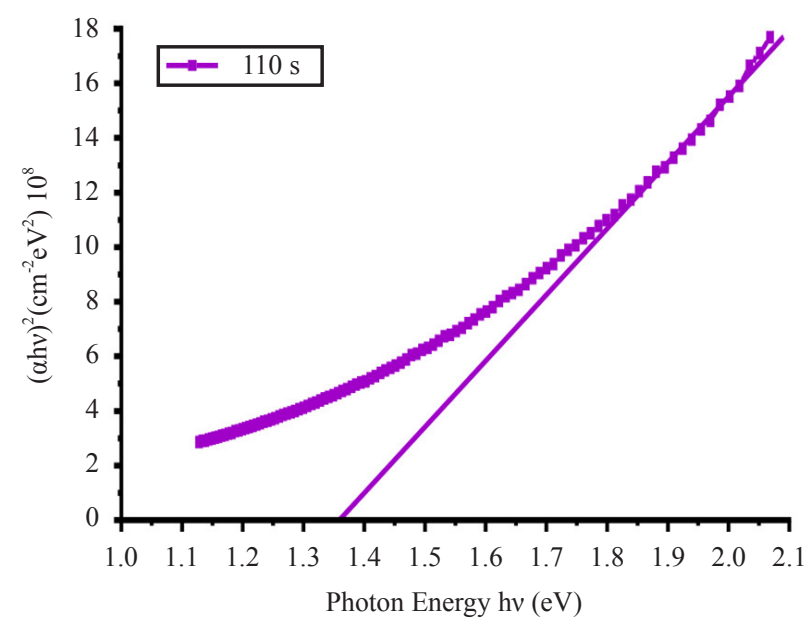

Figure 7. Plots of $(\alpha h v)^{2}$ against photon energy $(h v)$ for the deposited films

The plot of $(\alpha h v)^{2}$ against photon energy $(h v)$ for determination of the optical bandgap energy of the films is displayed in Figure 7. From the figure, the bandgap energy of the deposited thin films as obtained by extrapolating the straight-line portion of the curves of the plots of the samples along the photon energy $(h v)$ axis are $1.51 \mathrm{eV}, 1.54 \mathrm{eV}, 1.60$ $\mathrm{eV}, 1.45 \mathrm{eV}$, and $1.35 \mathrm{eV}$ for the films deposited at $30 \mathrm{~s}, 50 \mathrm{~s}, 70 \mathrm{~s}, 90 \mathrm{~s}$, and $110 \mathrm{~s}$ respectively. These results show that the bandgap energy of $\mathrm{PbS}$ has been blue-shifted by incorporating manganese into its crystal structure and the values of the bandgap energy are in the solar spectrum range suitable for photovoltaic cell and photodetector applications. This result is similar to the report for PbMnS deposited at voltage variation as given by [31].

\subsection{Structural properties}

The XRD patterns of the deposited thin films of PbMnS obtained from the XRD analysis done to investigate their structural properties are displayed in Figure 8. The XRD patterns show that the films are crystalline with sharp peaks that occurred at two theta positions that correspond to crystalline planes of (111), (200), (211), (220), (311), and (400). These peaks almost match with the standard data (JCPDS Nos. 01-078-1055 and 01-076-2049) indexed to the cubic crystal structures of $\mathrm{PbS}$ and $\mathrm{MnS}_{2}$ respectively. The crystallite size $(D)$, dislocation density $(\delta)$, and micro-strain $(\varepsilon)$ of the films were calculated using the Dybe-Scherer and Williamson-Smallman relation as given by [32-34].

$$
\begin{aligned}
& D=\frac{k \lambda}{\beta \operatorname{Cos} \theta} \\
& \delta=\frac{1}{D^{2}} \\
& \varepsilon=\frac{\beta}{4 \tan \theta}
\end{aligned}
$$

Where $k$ is the shape factor, $\lambda$ is the $\mathrm{x}$-ray wavelength, $\beta$ is the full weight at half maximum (FWHM) and $\theta$ is Bragg's angle. Table 2 shows the values of crystallite size, dislocation density, and microstrain of the deposited $\mathrm{PbMnS}$ thin films. The average crystallite size of the films showed an increasing trend while the dislocation density and micro-strain showed a decrease with the increase in deposition time. This slight increase in the crystallite size may be attributed to the increase in the film thickness observed at $70 \mathrm{~s}$ which also resulted in large particle sizes as could be seen from the SEM image. 


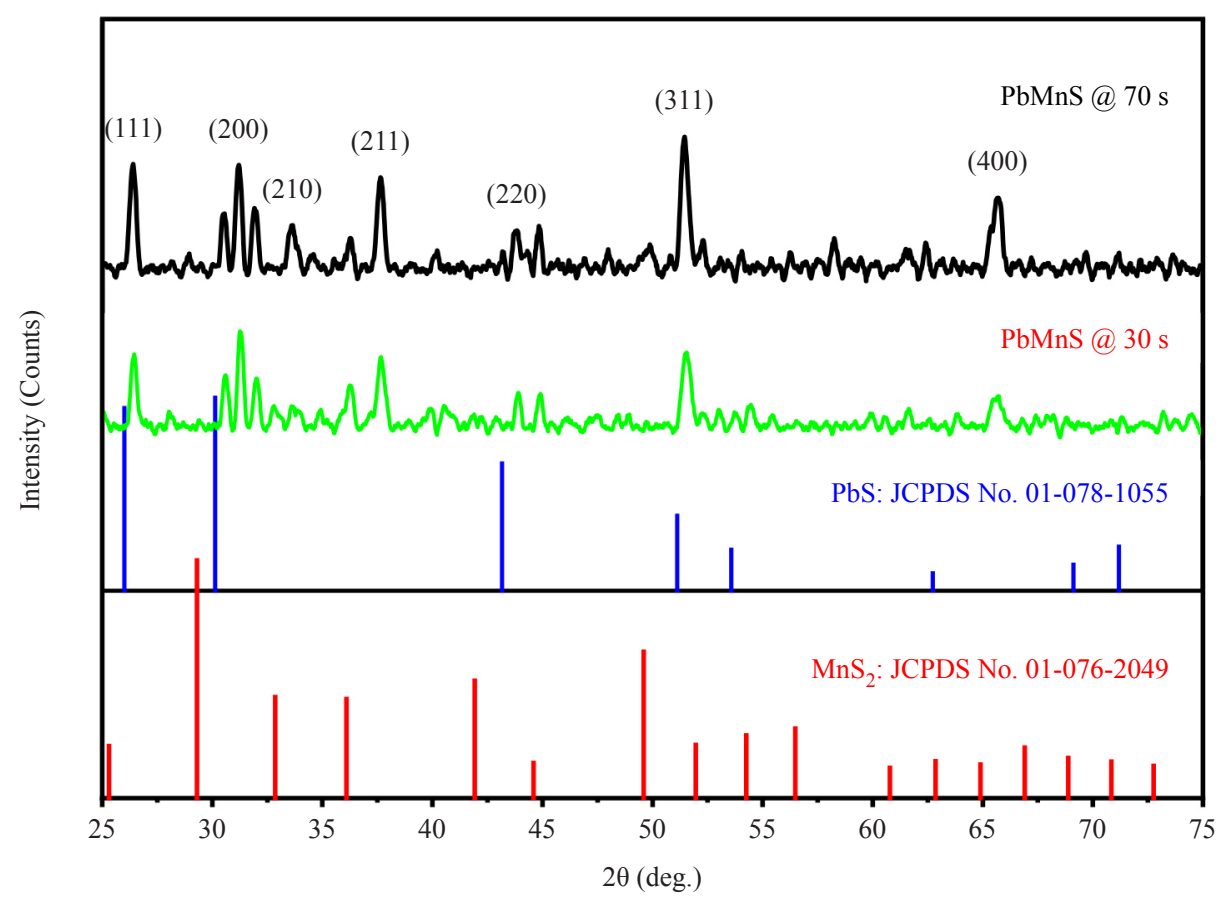

Figure 8. XRD patterns of the deposited thin films of PbMnS

Table 2. Average crystallite size, dislocation density, and micro-strain for deposited PbMnS thin films

\begin{tabular}{|c|c|c|c|c|c|c|}
\hline Samples & $2 \theta(\operatorname{deg})$ & h k 1 & FWHM (deg) & Crystallite Size D (nm) & $\begin{array}{l}\text { Dislocation Density } \delta \times 10^{-3} \\
\quad\left(\text { lines } / \mathrm{nm}^{2}\right)\end{array}$ & Micro-strain $(\varepsilon) \times 10^{-3}$ \\
\hline \multirow{5}{*}{$30 \mathrm{~s}$} & 26.44 & 111 & 0.496 & 17.184 & 3.387 & 5.926 \\
\hline & 31.29 & 200 & 0.446 & 19.320 & 2.679 & 17.393 \\
\hline & 44.14 & 220 & 2.123 & 4.217 & 56.224 & 11.013 \\
\hline & 51.54 & 311 & 0.442 & 20.846 & 2.301 & 3.604 \\
\hline & 65.64 & 400 & 0.520 & 18.985 & 2.774 & 3.383 \\
\hline \multicolumn{4}{|c|}{ Average } & 16.110 & 13.473 & 9.305 \\
\hline \multirow{5}{*}{$70 \mathrm{~s}$} & 26.39 & 111 & 0.319 & 26.718 & 1.401 & 9.214 \\
\hline & 31.20 & 200 & 1.113 & 7.740 & 16.692 & 6.950 \\
\hline & 44.17 & 220 & 1.024 & 8.744 & 13.078 & 22.847 \\
\hline & 51.46 & 311 & 0.398 & 23.142 & 1.867 & 3.995 \\
\hline & 65.64 & 400 & 0.500 & 19.747 & 2.565 & 3.519 \\
\hline \multicolumn{4}{|c|}{ Average } & 17.218 & 7.121 & 8.264 \\
\hline
\end{tabular}

\subsection{Morphological properties}

Figure 8 is the SEM image of the deposited thin films of PbMnS. From the figure, it can be seen from the SEM 
image/morphology that the particle sizes of the films are uniformly packed together on the surface of the FTO glass substrate. The particle sizes are spherical in shape, uniform in size, and densely packed together thus revealing the rough nature of the surface of the films. However, the particle size of the films can be observed to increase to the largest sizes as time increased to $70 \mathrm{~s}$ and then decreased as the time of deposition increased further. The morphology of the films further indicates that there are no pores of hollows on the surface of most of the films thus confirming the crystalline nature of the deposited thin films.

$30 \mathrm{~S}$

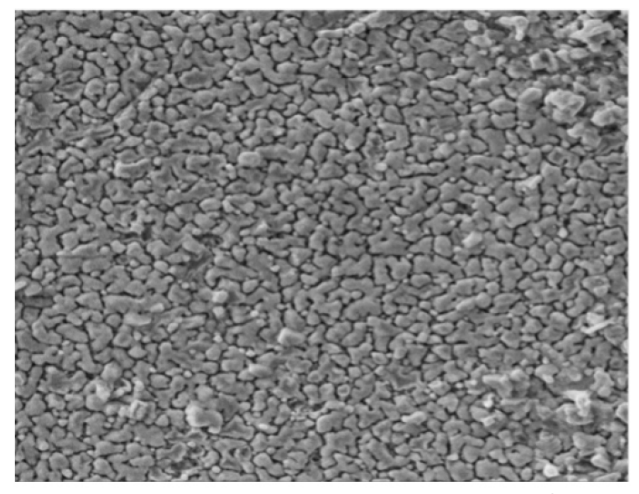

$\longrightarrow 2 \mu \mathrm{m}$

$70 \mathrm{~S}$

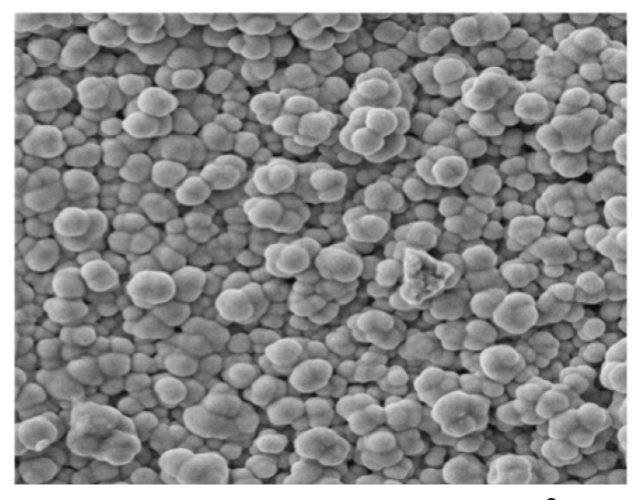

$2 \mu \mathrm{m}$
$50 \mathrm{~S}$

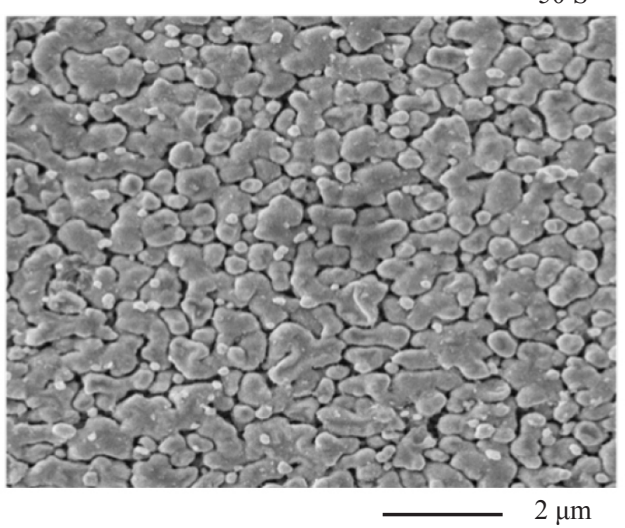

$90 \mathrm{~S}$

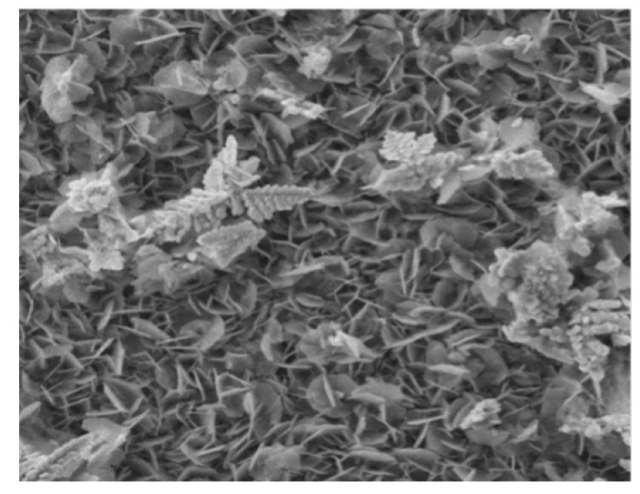

$2 \mu \mathrm{m}$

$110 \mathrm{~S}$

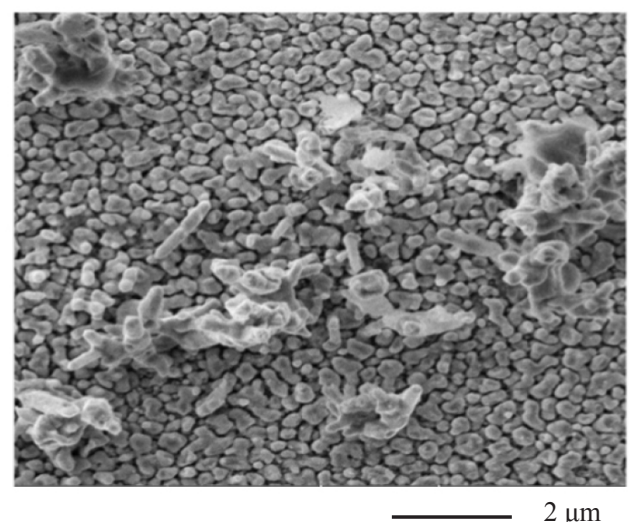

Figure 9. SEM micrographs of the deposited thin films of PbMnS 


\subsection{Elemental composition of the deposited thin films}

Figure 10 is the EDX spectrum analysis carried for the film of PbMnS deposited at $70 \mathrm{~s}$ to determine the elemental composition of the films. The figure showed that the target elements; lead, manganese, and sulfur are present in the deposited films. However, some impurities such as oxygen, sodium, tin, and carbon were also detected. The atomic weight percent of these elements for five different spectra focused in the film is shown in Table 3 . The atomic weight percent of lead in the film was found to be greater than sulfur and manganese while the high percentage weight of tin and oxygen can be attributed to the FTO substrate used for the film deposition.

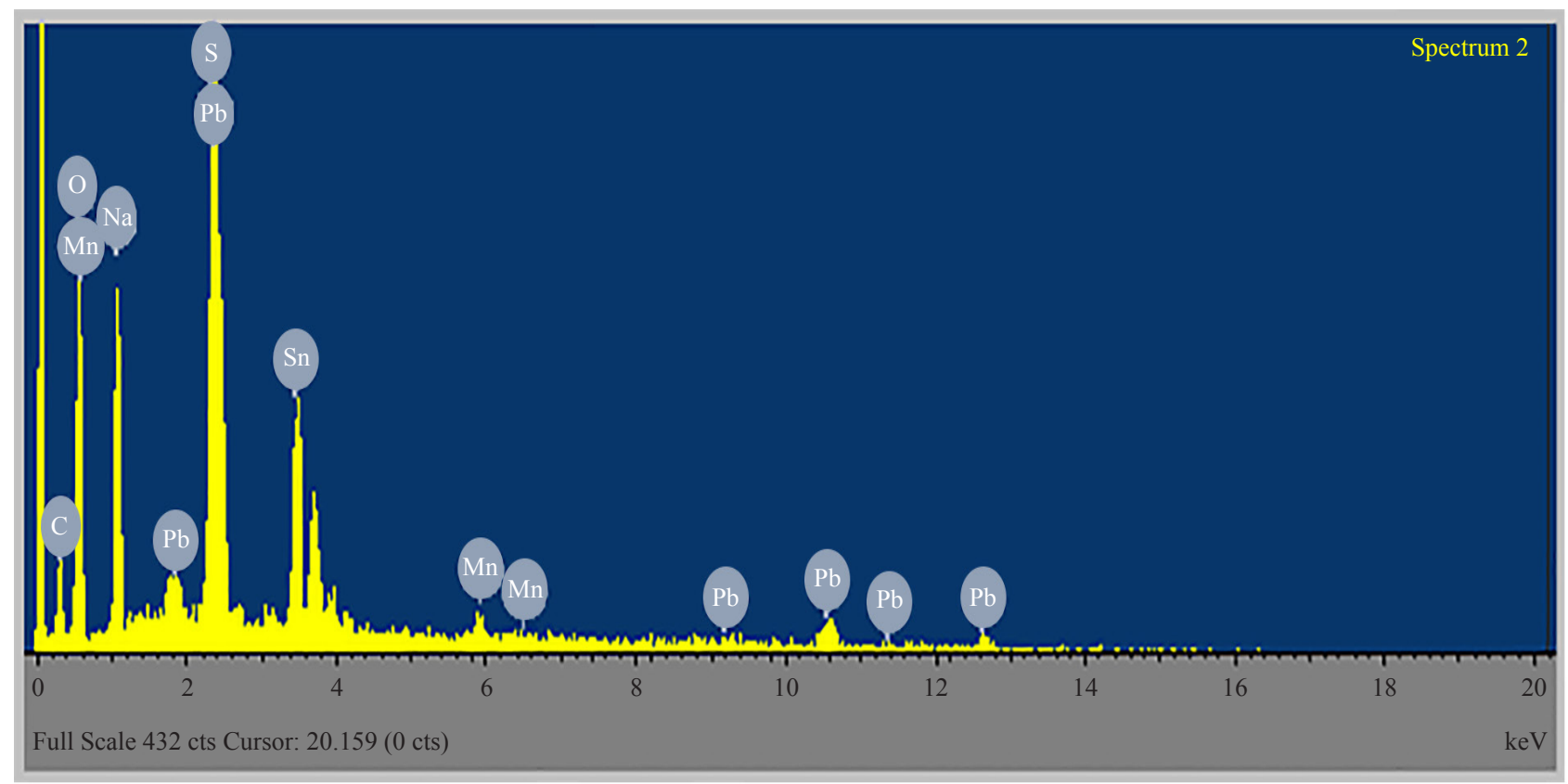

Figure 10. EDX spectrum for $\mathrm{PbMnS}$ at $70 \mathrm{~s}$ deposition time

Table 3. EDX weight percent for deposited PbMnS thin films using five spectrums focused at five different areas

\begin{tabular}{ccccccccc}
\hline Samples & \multicolumn{7}{c}{ Elements (Weight $\%$ ) } \\
\hline PbMnS (70 s) & $\mathrm{C}$ & $\mathrm{O}$ & $\mathrm{Na}$ & $\mathrm{Sn}$ & $\mathrm{Pb}$ & $\mathrm{Mn}$ & $\mathrm{S}$ & $\mathrm{T}$ \\
Spectrum 1 & 7.24 & 38.56 & 9.85 & 20.62 & 17.80 & 1.50 & 4.43 & 100 \\
Spectrum 2 & 8.77 & 33.48 & 10.22 & 18.22 & 23.68 & 1.45 & 4.18 & 100 \\
Spectrum 3 & 10.98 & 34.99 & 11.05 & 15.31 & 21.53 & 0.71 & 5.43 & 100 \\
Spectrum 4 & 6.97 & 38.91 & 11.73 & 16.18 & 19.79 & 1.13 & 5.30 & 100 \\
Spectrum 5 & 6.67 & 30.62 & 3.35 & 45.17 & 12.98 & 1.68 & 1.53 & 100 \\
Mean & 7.72 & 35.32 & 9.24 & 23.10 & 19.16 & 1.29 & 4.17 & 100 \\
\hline
\end{tabular}




\section{Conclusion}

The results of the investigations of the properties of the electrodeposited PbMnS thin films showed that the spectral absorbance, refractive index, and optical conductivity of the films are generally high in both the VIS and NIR regions of the electromagnetic spectrum with the maximum values exhibited by the film deposited at the time of $70 \mathrm{~s}$. The transmittance, reflectance, and extinction coefficient are low and decrease with an increase in deposition time in the two regions influenced by the deposition time. The direct bandgap energy of the films is found to be $1.51 \mathrm{eV}, 1.54 \mathrm{eV}$, $1.60 \mathrm{eV}, 1.45 \mathrm{eV}$, and $1.35 \mathrm{eV}$ for the films deposited at $30 \mathrm{~s}, 50 \mathrm{~s}, 70 \mathrm{~s}, 90 \mathrm{~s}$, and $110 \mathrm{~s}$ respectively. These values of bandgap energy indicate that the PbS has been blue-shifted as a result of the incorporation of $\mathrm{Mn}^{2+}$ in its crystal lattice. The XRD analysis showed that the films are crystalline with two theta peak positions indexable to crystalline planes of (111), (200), (211), (220), (311) and (400) for cubic crystal structures of PbS and $\mathrm{MnS}_{2}$. The average crystallite size was found to increase slightly from $16.110 \mathrm{~nm}$ to $17.218 \mathrm{~nm}$ as deposition time increased while the dislocation density and micro-strain decreased from $13.473 \times 10^{-3}$ lines $/ \mathrm{nm}^{2}$ to $7.121 \times 10^{-3}$ lines $/ \mathrm{nm}^{2}$ and $9.305 \times 10^{-3}$ to $8.264 \times 10^{-3}$ as deposition time increases respectively. The SEM morphology showed that the films have no pores or hollows hence confirming the crystalline nature of the deposited thin films of PbMnS. The EDX analysis showed that the films are composed of the target elements; lead, manganese, and sulfur but there are some impurities present in the deposited films which are attributed to the substrate used. These properties exhibited by the deposited thin films of PbMnS showed that they can serve as good materials for photodetector applications (sensors, photoconductors, etc.) and photovoltaic cell development for solar energy harnessing.

\section{Acknowledgements}

We are pleased to appreciate and acknowledge Mr. Whyte F. M., Mr. Nsude Kingsley Ugonna, and Mrs. Nsude Ebere of Nanotech Laboratory, University of Nigeria Nsukka (UNN), Nigeria for their help in carrying out optical characterization, Nura Adamu Mohammed of National Geosciences Research Laboratory, Nigeria Geological Survey Agency, Kaduna State Nigeria for helping in carrying out XRD analysis and Mrs. Miranda Waldron with her team of scientists at Electron Microscope Unit, University of Cape Town South Africa for making their laboratory available to carry out SEM characterization on our samples.

\section{Conflict of interest}

The authors declare no competing financial interest of any form during the progress of this work.

\section{References}

[1] Barrios-Salgado E, Rodr-guez-Lazcano Y, Pérez-Orozco JP, Colin J, Altuzar P, Campos J, et al. Effect of deposition time on the optoelectronics properties of $\mathrm{PbS}$ thin films obtained by microwave-assisted chemical bath deposition. Advances in Condensed Matter Physics. 2019; 2019(4): 1-8. Available from: https://doi. org/10.1155/2019/5960587.

[2] Hussain A, Begum A, Rahman A. Characterization of nanocrystalline lead sulphide thin films prepared by chemical bath deposition technique. Arabian Journal for Science and Engineering. 2013; 38(1): 169-174.

[3] Zaini MS, Liew JYC, Ahmad SAA, Mohmad AR, Kamarudin MA. Quantum confinement effect and photoenhancement of photoluminescence of $\mathrm{PbS}$ and $\mathrm{PbS} / \mathrm{MnS}$ quantum dots. Applied Science. 2020; 10(18): 1-10. Available from: https://doi.org/10.3390/app10186282.

[4] Gode F, Baglayan O, Guneri E. P-type nanostructure PbS thin films prepared by the SILAR method. Chalcogenide Letters. 2015; 12(10): 519-528. Available from: https://www.researchgate.net/publication/284734117.

[5] Rajathi S, Kirubavathi K, Selvaraju K. Preparation of nanocrystalline Cd-doped PbS thin films and their structural and optical properties. Journal of Taibah University for Science. 2017; 11(6): 1296-1305. Available from: https:// doi.org/10.1016/j.jtusci.2017.05.001. 
[6] Ikhioya IL, Ehika S, Omehe NN. Electrochemical deposition of lead sulphide (PbS) thin films deposited on zinc plate substrate. Journal of Materials Science Research and Reviews. 2018; 1(3): 1-11.

[7] Okafor PC, Ekpunobi AJ. The effect of manganeses percentage doping on the thickness and conductivity of copper sulphide nano films prepared by electrodeposition method. International Journal of Science \& Engineering Research. 2016; 7(2): 174-177.

[8] Jahan S, Liton MNH, Khan MKR, Rahman MM. Effect of aluminum doping on the properties of spray deposited copper sulphide $\left(\mathrm{Cu}_{2} \mathrm{~S}\right)$ thin films. International Journal of Advanced Engineering Technology. 2015; 6(1): 23-27.

[9] Priyadharshini P, Revathy R. Synthesis and characterization of metal doped nano crystallinn copper sulphide. International Journal of Recent Scientific Research. 2015; 6(4): 3328-3331.

[10] Luo D, Wang L, Qiu Y, Huang R, Liu B. Emergence of impurity-doped nanocrystal light-emitting diodes. Nanomaterials. 2020; 10(6): 1226. Available from: https://doi.org/10.3390/nano10061226.

[11] Okafor PC, Ekpunobi AJ. Effect of manganese doping percentage on band gap energy of cadmium sulphide (CdS) nano-films prepared by electrodeposition method. International Journal of Science and Research. 2015; 4(12): 2280-2284.

[12] Arbi N, Assaker IB, Gannouni M, Krisa A, Chtourou R. Effect of manganese concentration on physical and electrochemical properties of $\mathrm{Mn}^{2+}$ doped $\mathrm{ZnS}$ thin films deposited onto ITO (glass) substrates by electrodeposition technique. Journal of Materials Science: Materials in Electronics. 2017; 28: 4997-5005. Available from: https:// doi.org/10.1007/s10854-016-6155-0.

[13] Yost AJ, Pimachev A, Rimal G, Tang J, Dahnovsky Y, Chien T. Effects of Mn dopant locations on the electronic bandgap of PbS quantum dots. Appllied Physics Letters. 2017; 111(23): 1-5. Available from: https://doi. org/10.1063/1.5004463.

[14] Chidambara Kumar KN, Khadeer Basha SK, Shakil Muhammad G. Structural, optical and magnetic studies of Mn doped PbS thin films by SILAR method. Elixir Thin Film Technology. 2014; 76: 28336-28340.

[15] AlFaify S. Investigating the effects of manganese dopant on the structure, morphology and optical properties of the nano lead sulfide thin film. King Khalid University (KKU) Journal of Basic and Applied Sciences. 2016; 2(2): 1822.

[16] Gülen Y. Characteristics of Ba-doped PbS thin films prepared by the SILAR method. Acta Physica Polonica A. 2014; 126(3): 763-769. Available from: https://doi.org/10.12693/APhysPolA.126.763.

[17] Rajashree C, Balu AR, Nagarethinam VS. Infuence of Al doping on the structural, morphological and optoelectrical properties of spray deposited lead sulfde thin flms. Journal of Materials Science: Materials in Electronics. 2016; 27: 7876-7882. Avaible from: https://doi.org/10.1007/s10854-016-4778-9.

[18] Saravanan RSS, Meena M, Pukazhselvan D, Mahadevan CK. Structural, optical and electrical characterization of $\mathrm{Mn}^{2+}$ and $\mathrm{Cd}^{2+}$ doped/codoped PbS nanocrystals. Journal of Alloys Compound. 2015; 627: 69-77.

[19] Ahmed AM, Mohamed R, Mohamed S. The structure and photoelectrochemical activity of Cr-doped PbS thin films grown by chemical bath deposition. Royal Society of Chemistry Advances. 2020; 10: 14458-14470.

[20] Ikhioya IL, Okanigbuan PN, Agbakwuru CB, Osolobri BU. Characterization of zinc sulphide/cadmium sulphide $(\mathrm{ZnS} / \mathrm{CdS})$ superlattice by electrodeposition technique. Journal of the Nigerian Association of Mathematical Physics. 2015; 29: 331-338.

[21] Kariper İA, Ozden S, Tezel FM. Optical properties of selenium sulfide thin film produced via chemical dropping method. Optical and Quantum Electronics. 2018; 50: 441. Available from: https://doi.org/10.1007/s11082-0181693-8.

[22] Yahya AM, Mahdi ZF, Faris RA, Mohammed GH. Effect of the thickness on the optical properties of nanostructure CuS thin films. Chemistry and Materials Research. 2014; 6(2): 47-54.

[23] Ezenwaka LN, Okoli NL, Okereke NA, Ezenwa IA, Nwori AN. Properties of electrosynthesized cobalt doped zinc selenide thin films deposited at varying time. Journal of Nanoarchitectonics. 2022; 3(1): 1-17.

[24] Egwunyenga NJ, Ezenwaka NL, Ezenwa IA, Okoli NL. Effect of annealing temperature on the optical properties of electrodeposited $\mathrm{ZnO} / \mathrm{MgO}$ superlattice. Materials Research Express. 2019; 6(10): 1-9. Available from: https:// doi.org/10.1088/2053-1591/ab42ab.

[25] Sangamesha MA, Pushpalatha K, Shekar GL, Shamsundar S. Preparation and characterization of nanocrystalline $\mathrm{CuS}$ thin films for dye-sensitized solar cells. International Scholarly Research Notices. 2013; 2013: 1-8. Available from: https://doi.org/10.1155/2013/829430.

[26] Ekpekpo A, Ufuoma IR. Characterization of copper sulfide (CuS) thin films syntheized by electroless plating. International Research Journal of Pure and Applied Physics. 2019; 6(1): 20-35.

[27] Barote MA, Yadav AA, Chavan TV, Masumdar EU. Characterization and photoelectrochemical properties of chemical bath deposited n-PbS thin films. Digest Journal of Nanomaterials and Biostructures. 2011; 6(3): 979- 
990.

[28] Kariper İA, Göde F. Influence of $\mathrm{pH}$ on the structural and optical properties of polycrystalline MnTe2 thin films produced by chemical bath deposition method. Acta Physica Polonica A. 2017; 132(3): 531-534. Available from: https://doi.org/10.12693/APhysPolA.132.531.

[29] Hannachi A, Hammami S, Raouafi N, Maghraoui-Meherzi H. Preparation of manganese sulfide (MnS) thin films by chemical bath deposition: Application of the experimental design methodology. Journal of Alloys and Compounds. 2016; 663: 507-515. Available from: https://doi.org/10.1016/j.jallcom.2015.11.058.

[30] Karunakaran M, Maheswari S, Kasirajan K, Raj SD, Chandramohan R. Structural and optical properties of Mndoped $\mathrm{ZnO}$ thin films prepared by SILAR method. International Letters of Chemistry, Physics and Astronomy. 2017; 73: 22-30. Available from: https://doi.org/10.18052/www.scipress.com/ILCPA.73.22.

[31] Nwori AN, Ezenwaka LN, Ottih IE, Okereke NA, Umeokwona NS, Okoli NL, et al. Effect of deposition voltage variation on the optical properties of PbMnS thin films deposited by electrodeposition method. Journal of Physics and Chemistry of Materials. 2021; 8(3): 12-22.

[32] Hassan AI, Maki SI. Structural and optical properties of copper-doped cobalt oxide thin films prepared by spray pyrolysis. International Journal of Engineering Sciences \& Research Technology. 2017; 6(3): 527-535. Available from: https://doi.org/10.5281/zenodo.439223.

[33] Girija K, Thirumalairajan S, Mohan SM, Chandrasekaran J. Structural, morphological and optical studies of CdSe thin films from ammonia bath. Chalcogenide Letters. 2009; 6(8): 351-357.

[34] Prasoon P, Jayaram P, Sulfikkarali NK, Deepak NK. Micro-strain, dislocation density, surface morphology and optoelectronic properties of indium zinc oxide thin films. International Journal of Research in Advent Technology. 2018; 6(12): 3486-3491. 